Revista Destaques Acadêmicos, Lajeado, v. 9, n. 1, 2017. ISSN 2176-3070

DOI: http://dx.doi.org/10.22410/issn.2176-3070.v9i1a2017.1312

www.univates.br/revistas

\title{
PLANEJAMENTO DE CARREIRA: UM ESTUDO COM FORMANDOS DE ADMINISTRAÇÃO DE EMPRESAS
}

\author{
Luana Machado Pestka ${ }^{1}$, Gabriel Machado Braido², \\ Bernardete Bregolin Cerutti ${ }^{3}$
}

Resumo: O objetivo deste estudo foi identificar a autopercepção dos formandos de Administração de Empresas e suas Linhas de Formação Específicas, de uma Instituição de Ensino Superior (IES) do Rio Grande do Sul, do semestre B/2015, para saber se eles possuem planejamento de carreira e se aprovam a existência de uma disciplina desta natureza no currículo dos cursos. Por meio de uma amostra de 68 formandos, foi possível concluir que $54,4 \%$ realizam planejamento de carreira e $83,8 \%$ aprovam a oferta de disciplina com foco nesta temática no currículo dos seus cursos.

Palavras-chave: Planejamento. Carreira. Gestão. Formandos de Administração de Empresas.

\section{INTRODUÇÃO}

As organizações, no início do século XX, possuíam um sistema hierárquico autoritário, com atividades padronizadas, as quais não permitiam o aperfeiçoamento e crescimento dos trabalhadores no ambiente de trabalho. A cultura estabelecida era de atividades rotineiras e repetitivas, apego e cumprimento de normas internas, conformismo com as situações impostas pelos chefes e trabalho individualizado, além de não despertar no empregado a vontade de melhoria contínua.

Nessa ocasião, segundo Dutra (2010), algumas pessoas percebiam o desenvolvimento de carreira como uma responsabilidade primária, exclusiva da empresa, ou ainda, algumas achavam que a ascensão na carreira era uma questão de sorte, bastando estar no lugar certo na hora certa. A busca por

1 Bacharela em Administração. lpestka@univates.br

2 Doutorando em Administração pela Universidade do Vale do Rio dos Sinos (Unisinos). Professor assistente do Centro Universitário UNIVATES. gabrielb@univates.br

3 Doutoranda em Desenvolvimento Regional pela Universidade de Santa Cruz do Sul (UNISC). Professora assistente do Centro Universitário UNIVATES. bcerutti@univates.br 
bons profissionais ocorre de maneira intensa a partir da virada do século XXI (DESSLER, 2014), em que a economia e o mundo dos negócios trouxeram uma série de fatores que obrigaram os empregadores e empregados a saírem da zona de conforto, preparando-se para um mercado mais complexo e competitivo.

Nesse cenário, a percepção sobre carreira também sofreu alterações. Preocupados em manterem-se ativos, os empregados direcionam seus esforços para o sucesso da organização, atuando de forma ativa e contributiva, empreendendo em suas tarefas, visando atender da melhor maneira possível os clientes, adaptando-se às constantes mudanças do ambiente.

Assim, o tema planejamento de carreira começa a ganhar espaço na vida dos profissionais, nas universidades e na sociedade em geral. Se no passado a carreira era vista como um caminho a ser percorrido com a intenção de conseguir uma progressão na empresa, hoje esse conceito tornou-se mais amplo, entende-se que a carreira é um conjunto de conhecimentos, habilidades e atitudes que o profissional utiliza durante as fases da vida com o objetivo de manter a sua empregabilidade. Portanto, a carreira é composta por estágios da vida profissional de cada pessoa que são planejados e estruturados, buscando equilibrar suas próprias necessidades e das empresas (OLIVEIRA, 2013).

Neste contexto, este artigo visa identificar e analisar a autopercepção dos formandos de uma Instituição de Ensino Superior (IES) do Rio Grande do Sul, do semestre B/2015, do curso de Administração de Empresas e suas quatro Linhas de Formação Específicas (Análises de Sistemas, Comércio Exterior, Gestão em Turismo e Negócios Agroindustriais), quanto ao planejamento de carreira. Para atender a este propósito, o estudo está estruturado em seis capítulos. O primeiro capítulo é a Introdução, descrita acima; o segundo é a Fundamentação Teórica; o terceiro é o Método utilizado; o quarto é a Apresentação e Análise dos Dados e o quinto a Conclusão.

\section{FUNDAMENTAÇÃO TEÓRICA}

\subsection{Conceito de planejamento de carreira}

A carreira profissional é vista como uma sequência de atividades, experiências e decisões relacionadas ao trabalho, que contribuem para o desenvolvimento do indivíduo. Ela envolve estágios e transições que refletem necessidades, motivos, aspirações individuais e, também, expectativas e imposições da organização e da sociedade (DUTRA, 2010).

Para que as pessoas consigam passar por essas transições e experiências com êxito, é necessário que anteriormente tenham delineado os seus passos. Em vista disso, é preciso citar e analisar outro conceito que é o planejamento. Segundo Oliveira (2013), o planejamento de carreira refere-se a um conjunto de ações pensadas e estruturadas que evidenciam a evolução de cada indivíduo, 
de maneira interativa com as necessidades das empresas, dos indivíduos e das comunidades onde elas atuam.

Werther J. e Davis (1983) simplificam, explicando que o planejamento de carreira compreende o apontamento de metas, bem como os procedimentos utilizados para alcançá-los. Swartz (apud CARAVANTES; BJUR 1997) enfatiza que o planejamento individual é um processo que permite à pessoa definir seus valores (missão, visão, princípios), identificar seus desejos e necessidades, além de traçar objetivos e prazos. Ademais, Drucker (1992, p. 42) destacam que "o planejamento não diz respeito a decisões futuras, mas às implicações futuras de decisões presentes".

O planejamento de carreira é relevante na vida de qualquer profissional que se dedica anos para a formação acadêmica, visando encontrar uma atividade que condiz com suas expectativas. Logo, possibilita que as pessoas busquem em suas próprias competências e aspirações um posicionamento a fim de focar seus esforços em determinadas organizações e posições pretendidas (RIBEIRO et al., 2009).

Com base nesses conceitos, entende-se que o planejamento de carreira é a estruturação formal e documentada de todos os estágios da vida profissional de uma pessoa com seus sonhos, desejos, necessidades e metas bem definidos, estabelecendo para cada um deles ações e atividades a fim de que sejam alcançados. Porém, essa não é uma ferramenta inalterável, pelo contrário, é um estudo que necessita ser revisto de tempos em tempos de acordo com as particularidades de cada indivíduo (OLIVEIRA, 2013; FERNANDES, 2012).

Com base no entendimento do significado de carreira, no próximo item, descreve-se sobre a sua evolução.

\subsection{Evolução da carreira profissional}

A carreira pode ser percebida de uma maneira discreta na Sociedade Feudal, mesmo considerando que esse tenha sido um período onde havia poucas profissões e o cotidiano das pessoas era diferente do atual. Havia uma divisão forte entre o clero, a nobreza e o terceiro estado (artesãos, mercadores e camponeses), e a carreira era vista como a continuidade que os filhos davam ao trabalho desenvolvido por seus familiares, sendo que, para as classes mais ricas havia a possibilidade de profissionalização (CHANLAT, 1995).

Nos anos que se seguiram, a carreira foi sendo moldada de acordo com os acontecimentos sociais, culturais e econômicos que modificaram de forma gradativa e lenta o curso normal da história de cada país (MASCARENHAS, 2008). Segundo Chanlat (1995), a ideia de carreira mais próxima da que se conhece hoje, surgiu com o período industrial capitalista, o qual baseava-se nos princípios de igualdade, progresso e liberdade de êxito individual, onde as pessoas começaram a passar de uma condição social a outra. 
Para melhor entendimento da evolução da carreira nos anos posteriores, vê-se criterioso relacioná-la às três fontes histórias de riqueza, baseadas em Dessler (2014), no Quadro 1, a seguir.

Quadro 1 - Fontes histórias de riqueza e a relação com a evolução da carreira

\begin{tabular}{|c|c|c|c|}
\hline Foco & $\begin{array}{c}\text { Industrialização Clássica } \\
1900 \text { a } 1950\end{array}$ & $\begin{array}{l}\text { Industrialização } \\
\text { Neoclássica } \\
1950 \text { a } 1990\end{array}$ & $\begin{array}{c}\text { Era da Informação } \\
\text { Após } 1990\end{array}$ \\
\hline $\begin{array}{c}\text { Estrutura } \\
\text { organizacional } \\
\text { predominante }\end{array}$ & $\begin{array}{l}\text { Funcional, burocrática, } \\
\text { piramidal, centralizadora, } \\
\text { rígida e inflexível. EEnfase } \\
\text { nos departamentos. }\end{array}$ & $\begin{array}{l}\text { Matricial e mista } \\
\text { com ênfase na } \\
\text { departamentalização } \\
\text { por produtos / } \\
\text { serviços ou unidades } \\
\text { estratégicas de } \\
\text { negócios. } \\
\end{array}$ & $\begin{array}{l}\text { Fluída e flexível, } \\
\text { totalmente } \\
\text { descentralizada com } \\
\text { ênfase em redes de } \\
\text { equipes multifuncionais. }\end{array}$ \\
\hline $\begin{array}{c}\text { Cultura } \\
\text { organizacional }\end{array}$ & $\begin{array}{l}\text { Teoria X } \\
\text { Foco no passado, nas } \\
\text { tradições. Ênfase na } \\
\text { manutenção do status } \\
\text { quo. Valor à experiência } \\
\text { anterior. }\end{array}$ & $\begin{array}{l}\text { Transição. Foco no } \\
\text { presente. Ênfase na } \\
\text { adaptação ao ambiente. }\end{array}$ & $\begin{array}{l}\text { Teoria Y } \\
\text { Foco no futuro. Ênfase na } \\
\text { mudança e na inovação. } \\
\text { Valor ao conhecimento e } \\
\text { à criatividade. }\end{array}$ \\
\hline $\begin{array}{c}\text { Ambiente } \\
\text { organizacional }\end{array}$ & $\begin{array}{l}\text { Estático, previsível e } \\
\text { gradativas mudanças. } \\
\text { Poucos desafios } \\
\text { ambientais. }\end{array}$ & $\begin{array}{l}\text { Intensificação das } \\
\text { mudanças e maior } \\
\text { velocidade nos } \\
\text { processos de trabalho. }\end{array}$ & $\begin{array}{l}\text { Mutável, imprevisível, } \\
\text { turbulento, com grandes } \\
\text { e intensas mudanças } \\
\text { no ambiente interno e } \\
\text { externo. }\end{array}$ \\
\hline $\begin{array}{l}\text { Modo de gerir } \\
\text { pessoas }\end{array}$ & $\begin{array}{l}\text { Pessoas como fatores } \\
\text { de produção inertes e } \\
\text { estáticos, sujeitos a regras } \\
\text { e a regulamentos rígidos } \\
\text { para serem controlados. }\end{array}$ & $\begin{array}{l}\text { Pessoas como recursos } \\
\text { organizacionais } \\
\text { que precisam ser } \\
\text { administrados. }\end{array}$ & $\begin{array}{l}\text { Pessoas como seres } \\
\text { humanos proativos, } \\
\text { dotados de inteligência, } \\
\text { habilidades e que } \\
\text { devem ser motivados e } \\
\text { impulsionados. }\end{array}$ \\
\hline $\begin{array}{l}\text { Visão das } \\
\text { pessoas }\end{array}$ & $\begin{array}{l}\text { Pessoas como } \\
\text { fornecedoras de mão-de- } \\
\text { obra. }\end{array}$ & $\begin{array}{l}\text { Pessoas como recursos } \\
\text { da organização. }\end{array}$ & $\begin{array}{l}\text { Pessoas como } \\
\text { fornecedoras de } \\
\text { conhecimentos e } \\
\text { competências. }\end{array}$ \\
\hline Nomenclatura & Relações Industriais. & $\begin{array}{l}\text { Administração de } \\
\text { Recursos Humanos. }\end{array}$ & Gestão de Pessoas. \\
\hline
\end{tabular}

Fonte: Adaptado pelos autores, de Dessler (2014).

No início das transformações mais significativas ocorridas no mundo, as empresas tinham uma cultura forte de resistência às mudanças, persistindo durante anos em um sistema de gestão fechado. Com a industrialização, a necessidade de adaptação para que as empresas se mantivessem competitivas tornou-se mais evidente, fazendo com que as corporações começassem a buscar novas formas de gestão.

A velocidade das transformações e a abertura das fronteiras para o comércio entre países, instaurou a necessidade indispensável das empresas tornarem-se flexíveis, adaptativas e mais produtivas, a fim de garantirem 
a sua posição no mercado. É nesse contexto que surgiu uma nova visão do perfil profissional (DESSLER, 2014). As empresas modernas passam a atrair colaboradores que sejam empreendedores de sua própria carreira, que busquem aperfeiçoarem-se para agregar conteúdo ao seu trabalho e crescer junto com elas, elevando a qualidade de seus produtos e serviços (DUTRA, 2010).

Nas décadas de 80 e 90, com o surgimento das multinacionais, mudanças nos processos produtivos e barateamento dos custos, o mercado interno e externo tornou-se mais competitivo, levando as organizações a preocuparem-se em atender as demandas do mercado, e a relação entre o profissional e a empresa continuou a seguir as exigências ditadas pelas organizações. A consequência da globalização da informação mudou o cenário econômico, fazendo com que os profissionais se apresentassem de uma forma mais abrangente ao mercado de trabalho. Nesse mesmo cenário, o aumento da competitividade entre empresas nacionais e estrangeiras trouxe consigo exigências de conhecimentos, habilidades e atitudes que compõem o perfil profissional desejado pelo mercado. A relação entre as empresas e a forma de atuação dos profissionais passou a ser mais flexível, possibilitando que as pessoas trabalhem em casa e em mais de uma empresa.

Nessa perspectiva, observa-se que as mudanças gradativas que ocorreram no mercado e nas organizações implicaram diretamente na construção dos perfis profissionais. Esses processos são acompanhados por diversas gerações, as quais são explicadas a seguir.

\subsection{Relação entre a carreira e as gerações}

As características e atitudes relacionadas às gerações estão vinculadas diretamente à organização, à economia e ao desejo pela ascensão profissional. Essas gerações denominam-se Baby Boomers (nascidos entre 1946 e 1964); Geração X (nascidos entre 1965 e 1977); Geração Y (nascidos entre 1978 e 1989); e a Geração Z (nascidos a partir de 1990) (VELOSO et al. 2008; SHINYASHIKI, 2009).

A Geração Baby Boomers (BB) é composta por nascidos após o término da Segunda Guerra Mundial. O seu nome é resultado de uma alta taxa de natalidade percebida após o retorno dos soldados da guerra, bem como da necessidade de mais pessoas para reconstruir os países destruídos no período de guerra (OLIVEIRA, 2010). Essa geração tem os seus ideais enraizados no respeito, na ordem, na obediência, nos valores familiares e na disciplina no trabalho e estudo (OLIVEIRA, 2010).

Em relação ao trabalho e carreira, Veloso et al. (2008) afirma que os nascidos nessa geração são profissionais otimistas, motivados, leais, dedicados e comprometidos com as empresas onde trabalham, visto que desejam o reconhecimento e a fama, a fim de garantir status e ascensão profissional. Barbosa e Cerbasi (2009) complementam que para a geração BB o tempo e a 
produção são fatores relacionados, visto que a produtividade eficaz irá gerar um maior reconhecimento de suas competências, e como consequência, o retorno financeiro proporcionará uma vida mais estruturada e tranquila.

Os nascidos entre os anos de 1965 e 1977 pertencem à Geração X, nesse período a tecnologia começou a ganhar espaço, principalmente por meio da televisão, a qual interferiu no comportamento e nos valores, tornando-os mais consumistas. A dedicação ao trabalho, na maioria das vezes, é motivada pelo desejo de aquisição e consumo de determinados produtos divulgados nesse veículo de comunicação (OLIVEIRA, 2010).

Essa geração mantém certo conservadorismo nas atividades e decisões, no entanto, não se detém em padrões e exigências impostos pela sociedade. Segundo Oliveira (2010), é menos ousada na manifestação e nas opiniões, embora se mantivessem firmes em suas ideias e objetivos. A base familiar existente na geração anterior, dá espaço à flexibilidade e liberdade nas relações, enquanto a Geração X, desenvolveu um perfil mais egocêntrico, de autoconfiança e autossuficiência, levando-os a dar mais importância ao trabalho do que à família.

Com relação à carreira, essa é a geração que começa a preocupar-se com a necessidade de capacitação profissional para garantir uma posição vantajosa no mercado de trabalho. O seu perfil profissional já não se adequava mais às organizações antigas, por isso seus esforços focaram-se em empresas com estrutura informal (SANTOS, 2011).

Lombardia et al. (2008, p. 4) complementa afirmando que os integrantes da Geração $X$ " [...] são conservadores, materialistas e possuem aversão à supervisão. Desconfiam de verdades absolutas, são autoconfiantes, cumprem objetivos e não os prazos, além de serem muito criativos". Souza (2011), Huczok e Leme (2014) enfatizam que essa geração busca o sucesso e a satisfação pessoal no emprego, sem ser necessário sacrificar-se para conquistar promoções ou outros benefícios que melhorem as suas vidas.

Pertencem à Geração Y os nascidos entre 1978 e 1989. A palavra que os define melhor é o imediatismo, fruto de uma estreita relação que essas pessoas possuem com as diversas formas de tecnologia que avançaram nesse período (SANTOS, 2011). A inovação tecnológica alterou o perfil das pessoas tornandoas mais individualistas, ambiciosas, preocupadas com as práticas sustentáveis e os direitos humanos. Por outro lado, possuem uma grande capacidade de interagir e se comunicar com grupos, por isso são profissionais formadores de opinião, decididos e coletivos. Por se adaptarem facilmente a um contexto incerto, gostam de correr riscos e serem desafiados (OLIVEIRA, 2010; SANTOS, 2011).

Em virtude disso, os profissionais desta geração procuram por empresas modernas que lhe proporcionem novas experiências, independência e desafios, a fim de construir sua carreira de forma independente, mas em parceria com 
as organizações para ambos obterem sucesso (MENDES, 2012). Veloso (2008) corrobora que o trabalho para essa geração não é visto como uma obrigação ou necessidade, mas sim como uma questão de satisfação, aprendizado e compartilhamento de experiências.

A Geração Z é composta por nascidos na década de 1990 em diante (SHINYASHIKI, 2009). Por nascerem na Era da Informação, são pessoas conectadas, informadas e dependentes de todo o tipo de tecnologia. Essa geração é apontada como a mais consumista, individualista e ativa, e que provavelmente enfrentará dificuldades nas relações interpessoais (SOUZA, 2011).

A grande maioria das pessoas pertencentes a essa geração, estão ainda iniciando a vida acadêmica ou profissional, e direcionam seus esforços na busca por empresas que valorizem suas características pessoais e profissionais como o domínio de tecnologias, a conectividade, o diálogo, a velocidade e as multitarefas (MENDES, 2012).

De acordo com o Quadro 2, é possível visualizar e entender mais facilmente as características das gerações, segundo os autores Erickson (2011), Oliveira (2010), Lombardia (2008), Loiola (2009), Santos (2011), Souza (2011), Vannuchi e Duarte (2001).

Quadro 2 - Características das gerações

\begin{tabular}{|c|l|c|}
\hline Geração & \multicolumn{1}{|c|}{ Característica } & \multicolumn{1}{|c|}{ Autor } \\
\hline Baby & $\begin{array}{l}\text { Relacionamento de respeito e lealdade com } \\
\text { a família, colegas e trabalho. Importância do } \\
\text { sucesso profissional. Desejo de fazer a diferença, } \\
\text { competitivos e responsáveis. }\end{array}$ & ERICKSON (2011) \\
\cline { 2 - 3 } Boomers & $\begin{array}{l}\text { Eduçãa rígida, com disciplina, ordem e } \\
\text { obediência que culminou no desrespeito às } \\
\text { regras estabelecidas. Rebeldes e contestadores. } \\
\text { Expectativas na gratificação, crescimento pessoal, } \\
\text { bem-estar, saúde, sucesso profissional na mesma } \\
\text { empresa por muitos anos. }\end{array}$ & OLIVEIRA (2010) \\
\hline Geração X X & $\begin{array}{l}\text { Rebeldes, egocêntricos, não convencionais, } \\
\text { autoconfiantes. A maturidade veio cedo e com isso } \\
\text { buscam estabilidade e independência, colocam o } \\
\text { trabalho em primeiro lugar. }\end{array}$ & OLIVEIRA (2010) \\
\cline { 2 - 3 } $\begin{array}{l}\text { Conservadores, materialistas, avessos à supervisão, } \\
\text { otimistas, desconfiados, autoconfiantes, criativos e } \\
\text { cumpridores de objetivos. }\end{array}$ & LOMBARDIA (2008) \\
\hline
\end{tabular}




\begin{tabular}{|c|c|c|}
\hline Geração & Característica & Autor \\
\hline \multirow{3}{*}{ Geração Y } & $\begin{array}{l}\text { Buscam reconhecimento, gostam de desafios, são } \\
\text { informais e flexíveis, individuais e relacionais. }\end{array}$ & OLIVEIRA (2010) \\
\hline & $\begin{array}{l}\text { Ambiciosos, individualistas, instáveis, preocupados } \\
\text { com o meio ambiente e com os direitos humanos, } \\
\text { esperançosos, decididos e coletivos, consumistas e } \\
\text { multitarefeiros. }\end{array}$ & LOIOLA (2009) \\
\hline & $\begin{array}{l}\text { Ágeis, sensíveis a injustiças, impacientes, folgados, } \\
\text { distraídos, superficiais e insubordinados. }\end{array}$ & SANTOS (2011) \\
\hline \multirow{2}{*}{ Geração Z } & $\begin{array}{l}\text { Ansiosos e imediatistas, afetivos à tecnologia, } \\
\text { focados em resultados e não enxergam fronteiras. }\end{array}$ & SOUZA (2011) \\
\hline & Multitarefas e pensamento complexo. & $\begin{array}{l}\text { VANNUCHI, } \\
\text { DUARTE (2001) }\end{array}$ \\
\hline
\end{tabular}

Fonte: Adaptado pelos autores, de Meurer (2013, p. 38).

De acordo com Oliveira (2010), embora a maioria dos profissionais que atuam no mercado de trabalho pertença à Geração $\mathrm{Y}$ ou as suas antecessoras, é necessário preparar as organizações e os recursos humanos para o ingresso da Geração Z no mundo corporativo. O mesmo autor ressalta que ambas as gerações podem contribuir uma com a outra promovendo o trabalho harmonioso, mesmo com as diferenças.

\subsubsection{Desafios da transição de carreira}

Nas últimas décadas os ambientes organizacionais tornaram-se cada vez mais mutáveis e flexíveis, em virtude do surgimento de uma nova economia interdependente e dinâmica. A partir disso, houve também uma mudança no perfil profissional para atender às exigências das organizações. As pessoas buscaram se qualificar e se preparar para atuar em um determinado cargo ou função.

No entanto, ainda é necessário considerar que alguns profissionais podem desenvolver durante o trabalho outras vocações, desejos e curiosidades por novas áreas de atuação, levando-os a buscarem novos empregos e novas carreiras. Além disso, a transição de carreira também pode ocorrer por demissão, necessidade de manter o equilíbrio financeiro e desenvolvimento de carreira.

Nesse sentido, Dutra (2010) afirma que a transição de carreira é a modificação da identidade profissional ocorrida por uma escolha de mudança de emprego, função ou área de atuação. Essa escolha pode ser vista como um momento de realização pessoal e profissional, no entanto, a transição de carreira afeta toda a vida do indivíduo (familiar, financeira, social e econômica).

Para Schlossberg (1981, apud QUISHIDA; CASADO, 2009), a transição de carreira pode ser compreendida como a mudança da percepção que o indivíduo tem de si mesmo e do mundo onde vive, identificando oportunidades de 
desenvolvimento e satisfação, que implicará em mudanças de comportamento e relacionamento.

Bridges (2009, apud QUISHIDA; CASADO, 2009) afirma que os processos de transição ocorrem em três fases distintas. A primeira delas é o Fim, caracterizado pela renúncia de velhas atividades ou funções que não agregam valor ao indivíduo. A segunda etapa é a Zona Neutra, período no qual a pessoa abandonou antigos papéis, porém não assumiu a nova fase de sua vida, caracterizando um período de transição. E, a terceira fase é o Novo Começo, quando a transição desejada pelo indivíduo está em parte concluída e começa uma nova etapa da sua vida.

A mudança envolve um propósito de vida, por isso é importante ter certeza e vontade de mudar de área de atuação. Outro ponto a salientar é a necessidade de o profissional conhecer a si mesmo antes de optar por qualquer outra possibilidade de emprego. A identificação do talento natural e a demanda para o desempenho da nova atividade devem ser algo evidente, assim o profissional terá facilidade em inserir-se na nova área. A transição de carreira também deve ser pensada do ponto de vista financeiro, tendo em vista a necessidade de novos aprendizados formais ou, ainda, a possibilidade de dedicar-se exclusivamente a tal tarefa (TOZZI, 2011).

A mudança no foco profissional não tem idade para acontecer, podendo ser aos 25,35 ou 45 anos, no entanto, cada fase tem suas características e cenários que devem ser levados em consideração. Com a atual conjuntura da economia e da sociedade, e de desejos pessoais e familiares, surgem oportunidades além da área de formação inicial, sendo necessário, nesse processo de transição de carreira, a busca de novas fontes de conhecimentos para garantir a empregabilidade.

Na Era da Informação, em que as modificações ocorrem com frequência, não é mais possível permanecer no mercado com o mesmo perfil de antes. $\mathrm{O}$ mundo mudou, as ferramentas mudaram (DESSLER, 2014). Considerando o exposto, é importante analisar o papel das pessoas e das organizações na construção e gestão de carreira, conforme é descrito no próximo tópico.

\subsection{O papel das pessoas e das organizações na gestão de carreira}

Por muito tempo a gestão de carreira do funcionário foi entendida como função da organização em que o mesmo trabalhava. Com o passar dos anos, o nível de exigência do mercado elevou-se, fazendo com que os funcionários seguissem sua própria carreira com autonomia, sem depender exclusivamente do empregador. Nesse sentido, as organizações perceberam que era necessário melhorar a qualidade do trabalho, investindo no bem-estar e satisfação de colaboradores, e inseri-los de fato na organização por meio da difusão de seus propósitos (ROBBINS, 2002; MARQUEZE; MORENO, 2005). 
Com base nisso, o profissional tem se solidificado cada vez mais como uma importante parte da estrutura organizacional, compreendida como capital humano ou capital intangível. Seu conhecimento e sua experiência auxiliam na criação de novos produtos ou serviços, na solução de problemas e na tomada de decisões com eficácia (WOOD; PICARELLI, 2004).

Para Oliveira (2013), a tendência de atuação dos profissionais é de ampliar e interligar os seus conhecimentos e habilidades; assumir cargos de responsabilidade, conforme os resultados forem sendo alcançados; ter maior integração e conhecimento sobre a realidade da empresa e ter atitude para gerar diferencial no mercado de trabalho.

Por sua vez, cabe às empresas a incumbência de criar ambientes propícios e oferecer suporte para o desenvolvimento e crescimento de seus colaboradores. Contudo, Dutra (2002) destaca que para isso ocorrer, é necessária uma interação entre organização e funcionário. Pontes (2002) complementa afirmando que as organizações devem responsabilizar-se pela escolha de um plano de carreira a ser implementado, a fim de que seus colaboradores cresçam, assim como a organização. Mas, a decisão da trajetória de carreira é feita pelo funcionário.

Segundo Dessler (2014), para que as organizações consigam reter os seus talentos é importante que elas conheçam o perfil de cada um e reconheçam o indivíduo como parte fundamental da empresa, com suas motivações, emoções, sonhos e expectativas, pois à medida que a organização tem conhecimento de seus funcionários, torna-se mais fácil orientá-los na carreira, a fim de agregar valor à organização.

Na opinião de Oliveira (2013), o trabalho das empresas se dará fundamentalmente na viabilização da gestão de carreiras; na administração das competências identificadas e desejadas de seus colaboradores, bem como na promoção da educação corporativa. Nesse sentido, é cada vez mais possível visualizar a importância do empenho da empresa e das pessoas na administração e desenvolvimento de carreiras e o papel de cada uma delas na construção de uma relação em que ambos sejam beneficiados.

O principal ponto para uma boa administração de carreiras baseia-se em fornecer apoio e incentivo aos funcionários, para que possam aprimorar continuadamente seus conhecimentos e habilidades. Por outro lado, é necessário que os colaboradores conheçam suas características, a fim de que a negociação com a empresa seja alinhada às necessidades e expectativas de ambos.

\subsection{Competências necessárias para o desenvolvimento de carreira}

As mudanças no cenário econômico fizeram as organizações reestruturarem os seus sistemas produtivos, a fim de tornarem-se mais competitivos. Para isso, aderiram ao uso intenso de novas tecnologias que afetou diretamente o perfil profissional desejado. Estabeleceu-se, assim, um 
novo padrão de competências necessárias aos colaboradores para manterem-se empregados.

Nessa perspectiva, a importância da competência para o desenvolvimento de carreira pode ser compreendida a partir do seu conceito, que de acordo com Albuquerque e Leite (2009), é uma característica individual relacionada a três dimensões - conhecimento, habilidade e atitude - que faz com que cada indivíduo seja único e obtenha resultado diferente em situações semelhantes.

Compartilhando desse entendimento, Boog (1991) destaca que competência é a qualidade de quem é capaz de resolver certo assunto com habilidade e aptidão. É tudo o que o profissional precisa saber para desempenhar sua função. Logo, tudo o que ele precisa demonstrar como diferencial.

Leme (2005) também salienta que a competência possui três pilares, chamados Conhecimentos, Habilidades e Atitudes (CHA), que são distinguidos por competências técnicas (conhecimentos e habilidades) e competência comportamental (atitudes) de um indivíduo. A mesma autora enfatiza que o CHA é um conceito de competência elaborado em que os conhecimentos, as habilidades e as atitudes são indispensáveis para tornar o indivíduo capaz de se desenvolver completamente em uma organização, ou seja, uma pessoa não é totalmente competente se não possui um desses atributos.

O atual perfil também é citado por Dessler (2014), o qual ressalta que os novos profissionais se envolvem mais com as situações do ambiente de trabalho, agindo de forma criativa e empreendedora, buscando o sucesso do negócio e a melhoria de suas características profissionais, focando, também, seus esforços nos clientes internos e externos.

Independente do segmento da empresa (pública ou privada, industrial, comercial, prestação de serviços ou terceiro setor) e do porte, todas foram afetadas pela necessidade de contratar profissionais qualificados e preparados. Nesse sentido, Dessler (2014) destaca que as pessoas precisam administrar as suas atividades de forma independente e serem cada vez mais responsáveis e comprometidas pela melhoria contínua de seu trabalho, agregando valor aos seus serviços e tornando a organização bem-sucedida.

Em vista disso, é importante que os profissionais estejam atentos a essa demanda para se prepararem e conquistarem as oportunidades existentes no mercado de trabalho. Cabe salientar, conforme Oliveira (2013), que o diferencial dos profissionais está na capacidade de identificar oportunidades e aplicar seus conhecimentos na organização, além disso, é necessário investir no autoconhecimento, item abordado na sequência.

\subsection{Contribuição da universidade no desenvolvimento de carreiras}

De acordo com Dias (2009), a realidade acadêmica é diferente daquela em que o estudante vivenciava na escola, habituando-se a um ambiente com novas regras e rituais, vislumbrando a carreira de sucesso e oportunidades. 
Com o avanço da concorrência no mercado, percebe-se que para o universitário se tornar um profissional competente e de destaque em sua área, precisa adquirir conhecimento técnico-científico que o torne um agente capaz de contribuir no crescimento e desenvolvimento da sociedade. Considerando isso, entende-se que a universidade assume o papel de gerar, mediar e difundir esse conhecimento, com vistas à expansão contínua e equilibrada da qualidade de vida (pessoal e profissional).

O Ensino Superior interage entre o mercado carente de mão de obra qualificada e seus estudantes, dotados de conhecimentos e esperançosos por um emprego que lhe tragam realização. A universidade atua como um agente disseminador de culturas, preparando-os para o mercado de trabalho e para a relação de educação e estrutura socioeconômica que vive-se no momento (CAMBI, 1999; MANACORDA, 2007; SANTOS, 2005).

Na opinião de Gil (2012), a universidade proporciona, por meio de seus docentes, um ambiente propício para instruir, orientar, apontar, guiar, dirigir, formar, treinar, amoldar, preparar, doutrinar e instrumentar os seus alunos, a fim de tornarem-se profissionais mais completos no que tange às competências técnicas e comportamentais. Nesse sentido, Libâneo (2003, p. 1, texto digital) ressalta que a "[...] universidade existe para que os alunos aprendam conceitos, teorias; desenvolvam capacidade e habilidades; formem atitudes e valores e se realizem como profissionais-cidadãos".

Com a conclusão do curso universitário, o profissional vislumbra uma carreira bem-sucedida para poder, dentre outras coisas, constituir família, adquirir bens e ter uma vida econômica segura (DIAS, 2009). Portanto, é necessário considerar que nesse ponto, a qualidade da contribuição da universidade e o esforço empenhado pelo aluno, farão diferença no desenvolvimento e na gestão de carreira.

\section{MÉTODO}

Quanto à abordagem do problema, esta pesquisa possui natureza quantitativa, que de acordo com Roesch (2013), tem a finalidade de medir a relação entre variáveis ou resultados, a fim de estabelecer o comportamento de uma população. Para Malhotra, Montigelli Júnior e Farias (2012), a pesquisa quantitativa utiliza-se da linguagem matemática para estabelecer, definir e descrever as causas de um tema estudado, proporcionando melhor visão e compreensão do contexto do problema.

A pesquisa também é descritiva e exploratória. De acordo com Malhotra (2006, p. 102), a pesquisa descritiva "tem como principal objetivo a descrição de algo - normalmente características ou funções do mercado". E a etapa exploratória, segundo Gil (2010), proporciona mais intimidade com o problema e facilita a construção de hipóteses para a sua solução. Tem como objetivo o aperfeiçoamento das percepções. Neste estudo, a pesquisa descritiva 
e exploratória busca identificar os desafios percebidos pelos formandos ao concluírem o seu curso, e se o planejamento de carreira pode contribuir para minimizá-los. Além disso, por meio da autopercepção dos estudantes, é analisada a importância de uma disciplina específica que aborde o planejamento de carreira no currículo do curso.

A pesquisa foi aplicada a todos os formandos do semestre B/2015 do curso de Administração de Empresas e suas quatro Linhas de Formação Específicas, caracterizando-se como censo e não como amostra, em função da fácil localização da população-alvo. De acordo com Malhotra (2006, p. 320), censo consiste na "[...] enumeração completa dos elementos de uma população ou de objetos de estudo". Compartilhando deste entendimento, Marconi e Lakatos (2010, p. 206) destacam que a pesquisa censitária "abrange a totalidade dos componentes do universo". Destes, 68 responderam à pesquisa e 15 formandos não responderam, por não acessarem o $e$-mail durante o período de aplicação ou por opção de não responder. Mesmo assim, a pesquisa apresenta alta representatividade, com $82 \%$ da população-alvo.

Os dados foram coletados por meio da ferramenta online Google Docs, com 18 questões fechadas. O questionário é dividido em 7 eixos, conforme apresentado no Quadro 1, abaixo.

Quadro 3 - Base para elaboração do questionário

\begin{tabular}{|c|c|c|}
\hline Eixos & Aspectos identificados & Autores \\
\hline $\begin{array}{l}\text { Eixo I: Perfil } \\
\text { profissional do } \\
\text { respondente }\end{array}$ & $\begin{array}{l}\text { Gênero; faixa etária; tempo de atuação } \\
\text { na empresa; linha de formação; área(s) } \\
\text { profissional(is) em que atua no momento. }\end{array}$ & $\begin{array}{l}\text { Elaborado pelos } \\
\text { autores deste } \\
\text { estudo. }\end{array}$ \\
\hline $\begin{array}{l}\text { Eixo II: } \\
\text { Autopercepção } \\
\text { dos formandos } \\
\text { sobre } \\
\text { planejamento e } \\
\text { gestão de carreira }\end{array}$ & $\begin{array}{l}\text { Identificação com a(s) área(s) que trabalha; } \\
\text { satisfação com o cargo que ocupa; o planejamento } \\
\text { e a gestão de carreira são ferramentas relevantes } \\
\text { para o sucesso profissional; o planejamento e } \\
\text { a gestão de carreira proporcionam vantagem } \\
\text { competitiva; tem conhecimento sobre } \\
\text { planejamento e gestão de carreira. }\end{array}$ & $\begin{array}{l}\text { Chanlat (1996); } \\
\text { Dutra (2012); } \\
\text { Oliveira (2013); } \\
\text { Rosa (2011); } \\
\text { Vergara (2013). }\end{array}$ \\
\hline $\begin{array}{l}\text { Eixo III: Desafios } \\
\text { percebidos ao } \\
\text { término da } \\
\text { graduação }\end{array}$ & $\begin{array}{l}\text { Considerando a conclusão do curso de } \\
\text { graduação, quais são os principais desafios; } \\
\text { Considerando os desafios assinalados na questão } \\
\text { anterior, acredito que o Planejamento e a Gestão } \\
\text { de Carreira podem (ou poderiam) me ajudar na } \\
\text { superação dos mesmos. }\end{array}$ & $\begin{array}{l}\text { Albuquerque e } \\
\text { Leite (2009); Boog } \\
\text { (1991); Leme } \\
\text { (2005); Almeida } \\
\text { et al. (2001). }\end{array}$ \\
\hline $\begin{array}{l}\text { Eixo IV: } \\
\text { Realização do } \\
\text { planejamento de } \\
\text { carreira }\end{array}$ & $\begin{array}{l}\text { Nos últimos meses, tenho realizado planejamento } \\
\text { da minha carreira profissional. }\end{array}$ & $\begin{array}{l}\text { Rothweel e } \\
\text { Kazanas (1998, } \\
\text { apud DUTRA, } \\
\text { 2010); Xavier } \\
\text { (2006); Faria } \\
(2009) \text { e Oliveira } \\
(2013) \text {. }\end{array}$ \\
\hline
\end{tabular}




\begin{tabular}{|c|c|c|}
\hline Eixos & Aspectos identificados & Autores \\
\hline $\begin{array}{c}\text { Eixo V: } \\
\text { Abordagem } \\
\text { do tema } \\
\text { planejamento e } \\
\text { gestão de carreira } \\
\text { na graduação }\end{array}$ & $\begin{array}{l}\text { Durante o curso de graduação, o tema } \\
\text { Planejamento e Gestão de Carreira foi abordado } \\
\text { em alguma disciplina?; A oferta de uma } \\
\text { disciplina de Planejamento e Gestão de Carreira } \\
\text { no curso de graduação tem importância para } \\
\text { a formação acadêmica e preparação para o } \\
\text { mercado de trabalho. }\end{array}$ & $\begin{array}{l}\text { Dias (2009); } \\
\text { Cambi (1999); } \\
\text { Manacorda } \\
\text { (2007); Santos } \\
(2005) \text {. }\end{array}$ \\
\hline $\begin{array}{l}\text { Eixo VI: } \\
\text { Percepção dos } \\
\text { estudantes sobre } \\
\text { as empresas } \\
\end{array}$ & $\begin{array}{l}\text { Para trabalhar em uma empresa, avalio alguns } \\
\text { critérios. }\end{array}$ & $\begin{array}{l}\text { Almeida et al. } \\
(2001) ; \text { Oliveira } \\
(2013) \text {. }\end{array}$ \\
\hline $\begin{array}{c}\text { Eixo VII: } \\
\text { Percepção } \\
\text { em relação ao } \\
\text { mercado de } \\
\text { trabalho }\end{array}$ & $\begin{array}{l}\text { Analisando o atual momento da economia } \\
\text { e minha formação, considero-me preparado } \\
\text { para a inserção ou permanência no mercado de } \\
\text { trabalho. }\end{array}$ & $\begin{array}{l}\text { Libânio (1998); } \\
\text { Paschoal (2004); } \\
\text { Collares, Moysés } \\
\text { e Geraldi (1999). }\end{array}$ \\
\hline
\end{tabular}

Fonte: elaborado pelos autores (2015).

Na maioria das questões foi utilizada a escala Likert, que segundo Günther (2003, p. 11), é empregada “[...] especialmente em levantamentos de atitudes, opiniões e avaliações". A nomenclatura utilizada foi: concordo totalmente; concordo; não concordo, nem discordo; discordo; e discordo totalmente. Apenas nas questões em forma de pergunta, utilizou-se como opção de resposta: sim; não; e não lembro.

Antes de realizar a pesquisa o questionário foi aplicado a três formandos do curso de Administração de Empresas, com o objetivo de verificar falhas na escrita ou alguma opção faltante, interpretação difícil ou distorção das informações, sequência das questões e se o modelo utilizado de escala permitia a devida compreensão no momento da(s) escolha(s) da(s) resposta(s).

Após a coleta dos dados, foi realizado o processo de análise, utilizando a planilha eletrônica Microsoft Excel, a fim de produzir as informações necessárias para atendimento dos objetivos propostos. Assim, a seguir, são apresentados e discutidos os resultados da pesquisa.

\section{APRESENTAÇÃO E ANÁLISE DOS RESULTADOS}

Abrindo os resultados com base nos sete eixos da pesquisa, revela-se:

\subsection{Perfil profissional dos formandos}

Quanto ao gênero, 55,9\% dos respondentes são homens e $44,1 \%$ são mulheres. A presença maior de respondentes homens está relacionada ao fato de o público-alvo da pesquisa ser constituído de $55,4 \%$ de homens e $44,6 \%$ de mulheres, ou seja, há mais formandos homens no semestre B/2015. Da faixa 
etária, a maioria dos respondentes têm entre 21 a 25 anos, representando $41,2 \%$ dos formandos; seguido de 26 a 30 anos com 35,3\% dos formandos; de 31 a 35 anos com 13,2\% dos formandos; com mais de 35 anos representa 8,8\% dos formandos e com 16 a 20 anos, 1,5\% dos formandos. Se somadas, as duas faixas etárias que apresentam maior percentual são os que possuem 21 a 25 anos e 26 a 30 anos, totalizando $76,5 \%$ dos formandos.

Observa-se que a maioria dos respondentes pertencem às Gerações Y e Z. Essas gerações têm por características o imediatismo, a busca pelo conhecimento, o uso de tecnologias para descobrir novos saberes e os resultados a curto prazo (OLIVEIRA, 2010; LOIOLA, 2009). Isso pode justificar-se, pelo fato de que a maioria dos formandos está concluindo seu curso de graduação relativamente cedo, com idade igual ou inferior a 25 anos. Considerando as características dos respondentes, é relevante que as Instituições de Ensino e o seu corpo docente estejam atentos às demandas dessas gerações para que promovam com os acadêmicos uma relação de conhecimento e de crescimento, com ensino flexível, agregador e inovador (GIL, 2012).

Quanto ao tempo de atuação dos formandos no seu atual emprego, percebe-se uma variação, visto que há funcionários com menos de três anos e outros com mais de quinze anos de atuação. Entretanto, o tempo de trabalho que mais se sobressai é o da faixa de um a três anos com $38,2 \%$ dos formandos; seguido de 4 a 6 anos com 19,1\%; de 7 a 9 anos com 14,7\%; de 10 a 15 anos com 13,2\%, com mais de 15 anos atuando na mesma empresa 5,9\% dos formandos; e os respondentes desempregados somam $8,8 \%$, o que pode estar relacionado com a atual crise econômica enfrentada pelas empresas, as quais procuram realinhar investimentos e despesas.

Com base nas respostas, é provável que os formandos que atuam nas empresas de um a três anos pertençam a Geração $Y$, a qual caracteriza-se por não permanecer muitos anos na mesma organização. As pessoas pertencentes à essa geração desejam ter diversas experiências profissionais, viver novos desafios e ter maior interação com diversos públicos (OLIVEIRA, 2010). Por isso, é importante que as empresas implementem políticas de desenvolvimento de recursos humanos, a fim de possibilitar a permanência de profissionais na empresa, desenvolvendo trabalhos com eficácia, evitando a rotatividade, que se torna prejudicial à competitividade de uma organização.

Ainda, identificou-se que $77,9 \%$ dos respondentes são do próprio curso de Administração de Empresas; seguido das Linhas de Formação Específicas de Comércio Exterior, com 13,2\% dos respondentes; Análises de Sistemas e Negócios Agroindustriais com 4,4\% dos respondentes em cada curso. O curso de Gestão em Turismo possui dois formandos, os quais não responderam ao questionário.

Quanto as áreas em que os estudantes atuam no momento destaca-se a de Vendas, com 39,4\% dos formandos e a área Financeira-Orçamentária com $36,4 \%$ dos formandos. Na sequência Logística, com $22,7 \%$ dos formandos; 
Estratégia e Planejamento com 16,7\%; Marketing com 15,2\%; Produção 13,6\%; Recursos Humanos 12,1\%; Contabilidade 10,6\%; Sistemas de Informação 9,1\%; Materiais 7,6\%; Negócios Agroindustriais 3\%; Turismo 1,5\% dos formandos; e outras atividades com $22 \%$.

Nas atividades respondidas como "Outros", encontram-se as atribuições de Secretária Administrativa, Recepcionista, Caixa de Banco, Departamento Comercial, Proprietários de Empresas, Docência, Emissão de documentos relativos a processos de exportação, Almoxarifado/Manutenção, Negociação, Desempregado e Coordenação Administrativa.

O profissional formado em Administração de Empresas e suas Linhas de Formação Específicas, conforme estabelecido pelo Conselho Federal de Administração (CFA), está habilitado para atuar nas mais diversas áreas de uma organização, como Recursos Humanos; Materiais, Produção, Logística, Financeira-Orçamentária, Estratégica, Marketing, Vendas e Sistemas de Informação, percebido nas respostas, pois a maioria dos respondentes atuam na sua área de formação.

Quando questionados sobre a satisfação na atual atividade profissional, a maioria $(69,1 \%)$ dos formandos está satisfeita, entretanto, o percentual de insatisfação é significativo, representado por 30,9\% dos formandos. A satisfação no ambiente de trabalho é descrita por Robbins (2002) e Marqueze e Moreno (2005) como a atitude de uma pessoa em relação ao trabalho que realiza e complementam afirmando que a satisfação no trabalho resulta da avaliação que o profissional tem sobre o seu trabalho ou a realização de seus valores por meio dessa atividade.

\subsection{Autopercepção dos formandos sobre o planejamento e a gestão de carreira}

Identificou-se que 52,9\% dos respondentes concordam que o Planejamento e a Gestão de Carreira são ferramentas relevantes para o sucesso profissional, seguido de $45,6 \%$ dos respondentes que concordam totalmente com essa afirmação; e apenas 1,5\% dos respondentes não manifestaram opinião. Somando os percentuais mais elevados, chega-se ao índice de $98,5 \%$ dos respondentes que concordam que planejar e gerenciar a carreira proporcionará sucesso profissional. A partir desses resultados, percebe-se uma pré-disposição dos estudantes em conhecer mais sobre a temática. Conforme descrito por Dias e Soares (2009), o tema Planejamento de Carreira tem passado por mudanças e ganhado espaço na vida dos universitários, que estão preocupados em ascender profissionalmente em um contexto incerto e instável.

Nesse contexto, $57,4 \%$ dos formandos concordam que o Planejamento de Carreira proporciona vantagem competitiva, seguido de $39,7 \%$ dos formandos que concordam totalmente e de $2,9 \%$ dos formandos que não concordam, nem discordam da questão. Somando os que concordam, obtém-se o percentual 
de 97,1\% dos formandos. Segundo Dessler (2014), a vantagem competitiva é característica dos profissionais que possuem resultados superiores à média. A partir do exposto, entende-se que os formandos acreditam que estarão à frente dos seus concorrentes ao planejarem a sua carreira profissional e se prepararem para o mercado de trabalho cada vez mais exigente.

Diante disso, destaca-se a importância da existência de uma disciplina de Planejamento de Carreira para o curso de Administração de Empresas e suas Linhas de Formação Específicas, segundo apontamentos dos formandos do semestre $\mathrm{B} / 2015$.

\subsection{Desafios percebidos ao término da graduação}

Para $67,6 \%$ dos estudantes o maior desafio é conquistar o reconhecimento após a formação; seguido da conquista de aumento salarial com 51,5\%; do compromisso de aplicar os conhecimentos obtidos na graduação com $47,1 \%$; de investir em um negócio próprio com 44,1\%; de cursar pós-graduação em nível de especialização com $38,2 \%$; de repensar a carreira profissional com $26,5 \%$; da incerteza no futuro com $25 \%$; de buscar uma nova atuação e independência profissional com 22,1\% em cada opção; de participar de atividade de Educação Continuada para reciclagem de conhecimentos com 19,1\%; de cursar pósgraduação em nível de mestrado com 17, 6\%; de participar de processos de seleção na organização em que atua com $14,7 \%$; e de transição de carreira com $7,4 \%$ dos formandos.

Os percentuais demonstram que a maior parte dos estudantes desejam obter reconhecimento no seu ambiente de trabalho após a conclusão do curso. Segundo Robbins (2002), todos os profissionais exercem suas atribuições com o objetivo de serem reconhecidos pela empresa. Esse reconhecimento pode ser por meio de um elogio até a disponibilidade de programas individuais ou coletivos. A aprovação resulta na autoestima e no encorajamento para fazer o trabalho bem feito.

O segundo maior desafio verificado é a conquista de aumento salarial, que pode ser entendido como um reconhecimento material e incentivo ao crescimento profissional na organização, ou seja, o aumento salarial está atrelado ao reconhecimento do profissional. Do ponto de vista de Dessler (2014), o bom salário representa uma das buscas dos profissionais, pois os mesmos anseiam por poder aquisitivo, status social e valor individual.

Oterceiro maior desafio está em aplicar os conhecimentos obtidos durante vários anos de estudo, provavelmente em virtude da falta de oportunidade percebida pelos formandos. O quarto desafio destacado pelos respondentes é o de investir em um negócio próprio. Diante da atual situação econômica do país e da alta tributação brasileira, muitos profissionais não empreendem. O quinto desafio é cursar pós-graduação em nível de especialização, ou seja, percebe-se o grande interesse dos formandos em continuar qualificando-se, no entanto, a 
falta de planejamento financeiro e tempo podem ser o empecilho. Conforme explicado por Libâneo (2002), a Educação Continuada é o prolongamento da formação inicial, ou seja, a busca pelo conhecimento não deve acabar com a graduação, pois o aperfeiçoamento faz parte da trajetória profissional de todas as pessoas.

Considerando os desafios assinalados, questionou-se os estudantes se o Planejamento de Carreira pode (ou poderia) ajudar na superação dos mesmos. $86,8 \%$ dos respondentes concordam que planejar a carreira pode (ou poderia) ajudá-los na superação dos desafios indicados e, $13,2 \%$ dos respondentes não têm opinião formada sobre a contribuição do planejamento frente aos desafios. Sendo assim, acredita-se que a oferta de uma disciplina que aborde o tema de Planejamento de Carreira prepararia melhor os acadêmicos para o mercado de trabalho, especialmente após o término da graduação.

\subsection{Realização do planejamento de carreira}

Dos formandos, $54,4 \%$ realizam o planejamento da sua carreira profissional; $20,6 \%$ não realizam e $25 \%$ dos formandos não manifestaram opinião. Diante disso, acredita-se que o percentual de formandos que não tem conhecimento sobre o tema pesquisado conjecture na não realização do planejamento de sua carreira profissional. Isso evidencia o que os autores enfatizam, que embora o estudo do tema Planejamento de Carreira tenha se desenvolvido desde a década de 70 e ganhando espaço no cenário empresarial brasileiro somente a partir da década de 80 , vem se intensificando nos últimos anos, em virtude dos novos comportamentos e mudanças de postura que passam a ser exigidos pelas empresas e pela sociedade em geral (DUTRA, 1996).

Por curso e linha de formação específica, os acadêmicos que mais realizam planejamento de carreira, classificando-se da seguinte maneira: 66,7\% são da Linha de Formação em Negócios Agroindustriais; 56,6\% são da Linha de Formação em Comércio Exterior; $54,7 \%$ são específicos do curso de Administração de Empresas; e 33,3\% são da Linha de Formação em Análises de Sistemas. Percebe-se um porcentual considerável de formandos que realizam planejamento de carreira nas Linhas de Formação em Negócios Agroindustriais e Comércio Exterior, que se encontram em primeiro e segundo lugares, respectivamente. Provavelmente, o percentual elevado dos alunos da Linha de Formação em Negócios Agroindustriais que planejam a sua carreira profissional se deva ao envolvimento com micro e pequenos empreendimentos familiares. Para os alunos da Linha de Formação em Comércio Exterior, acredita-se que a prática do planejamento de carreira tem relação com a própria profissão, que requer conhecimentos e habilidades para atuar com as especificidades dos mercados nacionais e internacionais, sendo capaz de analisar situações e tendências mercadológicas, com ampla visão estratégica. 


\subsection{Abordagem do tema planejamento e da gestão da carreira na graduação}

Foi possível identificar qual o contato que os estudantes tiveram com o tema durante o seu curso de graduação, sendo que $58,8 \%$ dos formandos estudaram conteúdos relacionados a Planejamento de Carreira; $32,4 \%$ não lembram de terem estudado e $8,8 \%$ não estudaram. 59,1\% dos formandos de Administração de Empresas que não estudaram ou não lembram de ter estudado sobre o tema concordam que a disciplina deve existir; seguido da Linha de Formação em Comércio Exterior com 22,7\%; Negócios Agroindustriais com $13,6 \%$ e Análise de Sistemas com $4,5 \%$. A pesquisa ainda revela que $50 \%$ dos formandos concordam que a abordagem do tema de Planejamento de Carreira no seu curso de graduação proporcionará aos acadêmicos o maior preparo para atuar no mercado de trabalho; seguido de 33,8\% que concordam totalmente e $16,2 \%$ que não concordam, nem discordam.

Os dados revelam a aprovação dos estudantes em relação à existência de uma disciplina de Planejamento de Carreira no curso e nas linhas de formação específicas, por contribuir para a sua carreira profissional.

\subsection{Percepção dos estudantes em relação às empresas}

Identificou-se que $63,2 \%$ dos formandos avaliam salários e benefícios como um critério muito importante para permanecer na empresa; seguido da valorização profissional com 52,9\% dos formandos; ambiente de trabalho agradável com $51,5 \%$ dos formandos; plano de carreira e crescimento profissional $48,5 \%$ dos formandos; oportunizar novos desafios 39,7\% dos formandos; boa imagem no mercado $19,1 \%$ dos formandos; carreira internacional e flexibilidade de horários 7,4\% dos formandos em cada critério; e boa infraestrutura $4,4 \%$ dos formandos. Nenhum dos respondentes assinalou Plano de Participação nos Lucros e Resultados (PLR) como critério importante. Destaca-se, porém, que o primeiro e o segundo critérios indicados assemelham-se com os principais desafios que os formandos apontaram, ou seja, os estudantes desejam ser valorizados e reconhecidos no seu ambiente de trabalho, além de receberem salários e benefícios compatíveis com a função que desempenham.

Para Dessler (2014), Huczok e Leme (2014), os benefícios oferecidos são um complemento do salário do colaborador e ambos têm a capacidade de motivá-los. Percebendo isso, muitas empresas os oferecem como forma de atração e retenção de talentos. Esses investimentos, na maioria das vezes, fazem com que os profissionais se sintam valorizados, entretanto, a valorização vai além do reconhecimento financeiro, é necessário haver o respeito pelo profissional e suas competências; a aceitação de sugestões potenciais; a segurança em tomar as decisões e a perspectiva de crescimento.

O terceiro critério mais importante para os acadêmicos pesquisados é ter um ambiente de trabalho agradável, que proporcione conhecimento e desenvolvimento de habilidades e atitudes. Para isso ocorrer, segundo 
Gramigna (2002), é necessário também uma pré-disposição do colaborador em manter relações interpessoais saudáveis e harmônicas, estabelecendo vínculos entre os colegas de trabalho.

\subsection{Autopercepção dos estudantes em relação ao mercado de trabalho}

Observou-se que $89,7 \%$ dos formandos pretendem continuar estudando após o término da graduação, seja realizando cursos de Educação Continuada, especialização e/ou mestrado e 10,3\% dos formandos não pretendem realizar curso de aperfeiçoamento profissional. O elevado percentual de formandos que desejam aperfeiçoar seus conhecimentos reforça a explicação de Bastos (2008), que afirma que a Educação Continuada possibilita evoluções pontuais no conhecimento e na formação dos profissionais, além de permitir que estejam mais preparados para atuarem no mercado de trabalho. Neste contexto, as Instituições de Ensino Superior, segundo o mesmo autor, são responsáveis pela difusão do conhecimento, pela geração de novos saberes, proporcionando ao universitário uma formação de qualidade.

Neste contexto, 57,4\% dos formandos concordam que estão aptos para a inserção ou permanência no mercado de trabalho; $29,4 \%$ concordam totalmente; $11,8 \%$ dos formandos não concordam nem discordam; e 1,5\% dos formandos discordam. É possível visualizar, também, que a grande maioria se considera capacitado e preparado para as oscilações do mercado de trabalho. Dos seis formandos que estão desempregados, cinco consideram-se aptos para a inserção ou permanência no mercado de trabalho, e apenas um não manifestou opinião.

Realizando o cruzamento de dados é possível identificar que 88,9\% dos formandos da Linha Específica em Comércio Exterior acreditam estar preparados para o mercado de trabalho, seguido de 88,7\% dos formandos em Administração de Empresas; 66,7\% dos formandos das Linhas de Formação Específica em Negócios Agroindustriais e Análises de Sistemas.

Esse resultado pode ser percebido como reflexo do ensino proporcionado pela IES pesquisada, considerando sua infraestrutura de qualidade e didática utilizada no processo de ensino e aprendizagem, para que o conhecimento seja construído de forma gradual, preparando os estudantes para o mercado de trabalho. Libâneo (2003) corrobora que, as Instituições de Ensino têm como principal objetivo fazer com que os estudantes aprendam conceitos, teorias; desenvolvam capacidade e habilidades; a fim de formarem atitudes e se realizem como profissionais-cidadãos.

Embora os estudantes percebam diversos desafios nesse período de formação, acreditam que os anos de estudo e o ensino de qualidade proporcionado lhe permitirão vencer os desafios existentes no mercado de trabalho. Por fim, observa-se que a maior parte dos formandos no curso de Administração de Empresas e suas Linhas de Formação Específicas, do 
semestre B/2015, concordam com a existência de uma disciplina com foco em Planejamento de Carreira no currículo do curso.

\section{CONCLUSÃO}

Considerando a resposta dos 68 formandos, os resultados da pesquisa quanto ao perfil profissional indicam a predominância do sexo masculino, com 38 formandos ou 55,9\%; faixa etária entre 21 e 25 anos, representado por 28 formandos ou 41,2\%; e tempo de serviço no atual emprego de 1 a 3 anos, com 26 respondentes ou 38,2\%. Esses números revelam que os formandos são jovens.

A pesquisa também revelou que 37 formandos, o que significa $54,4 \%$ da amostra pesquisada, realizam planejamento da sua carreira profissional, no entanto, há alguns que não planejam e outros que se mostram indecisos, parecendo que às vezes planejam, outras vezes não.

Entre os formandos, $83,8 \%$ concordam com a oferta da disciplina sobre Planejamento de Carreira no currículo do curso. Cabe ressaltar que, mesmo acreditando estarem preparados para atuar no mercado de trabalho, os formandos apontam como relevante o estudo desse tema para a sua formação. Desse modo, acredita-se que a temática seja importante não somente para os formandos em Administração de Empresas como também para as Linhas de Formação, pois todos os formandos de duas das quatro Linhas de Formação que responderam à pesquisa (que são Análises de Sistemas e Negócios Agroindústrias) concordam com a oferta da referida disciplina no currículo do curso. Outro índice que se destacou neste estudo foi que $66,7 \%$ dos formandos da Linha de Formação em Negócios Agroindustriais e 56,6\% dos formandos da Linha de Formação em Comércio Exterior planejam a sua carreira profissional.

Considerando o exposto, acredita-se que o estudo dessa temática é importante não somente para os acadêmicos do curso de Administração de Empresas e as Linhas de Formação Específicas pesquisados, mas para todos os cursos oferecidos nessa IES, pois trata-se de saber planejar a carreira profissional. Nessa perspectiva de implementação, sugere-se estudar a viabilidade da oferta de uma disciplina eletiva para todos os cursos de graduação, focada em Planejamento de Carreira, com carga-horária de trinta horas, que objetive estimular e dar suporte ao estudante para um processo de autoavaliação, visando ao planejamento da carreira profissional; que desenvolva o espírito crítico e criativo em relação a seu comportamento diante da carreira; e também que desenvolva as competências para atuação no mercado de trabalho. Entre os conteúdos sugere-se Conceituação de competência; Identificação do perfil profissional; e Elaboração do planejamento e da gestão de carreira. Recomendase, ainda, que em cinco anos seja aplicada novamente a pesquisa, a fim de identificar se os acadêmicos continuam percebendo a importância da disciplina. 


\section{REFERÊNCIAS}

ALBUQUERQUE, Lindolfo Galvão de; LEITE, Nildes Pitombo. Gestão de pessoas: perspectivas e estratégias. São Paulo: Atlas, 2009.

BARBOSA, Christian; CERBASI, Gustavo. Mais tempo, mais dinheiro: estratégias para uma vida mais equilibrada. Rio de Janeiro: Thomas Nelson Brasil, 2009.

BOOG, Gustavo G. O desafio da competência. São Paulo: Best Seller, 1991.

CAMBI, F. História da pedagogia. São Paulo: UNESP, 1999.

CHANLAT, J. F. Quais carreiras e para qual sociedade. In: Revista de administração de empresas, São Paulo, v. 35, n. 6, p. 67-75, nov./dez. 1995.

CONSELHO FEDERAL DE ADMINISTRAÇÃO. Disponível em: <http:/ / www.cfa. org.br/fiscalizacao/campos-de-atuacao>. Acesso em: 03 out. 2015.

DIAS, Maria Sara de Lima. Planejamento de carreira: uma orientação para estudantes universitários. 1. ed. São Paulo: Vetor, 2009.

DESSLER, Gary. Administração de Recursos Humanos. 3. ed. São Paulo: Pearson Education do Brasil, 2014.

DRUCKER, Peter. Administrando para o futuro: os anos 90 e a virada do século. São Paulo: Pioneira, 1992.

DUTRA, Joel Souza. Gestão de pessoas: modelos, processos tendências e perspectivas. São Paulo: Atlas, 2002.

DUTRA, Joel Souza (Org.) Gestão de carreira na empresa contemporânea. São Paulo: Atlas, 2010.

DUTRA, Joel Souza. Administração de Carreiras: uma proposta para repensar a Gestão de Pessoas. 1. ed. São Paulo: Atlas, 2010.

Competências: conceitos e instrumentos para a Gestão de Pessoas na empresa moderna. 1. ed. São Paulo: Atlas, 2012.

ERICKSON, Tamara J. E agora geração X? Como se manter no auge profissional e exercer a liderança plena numa época de intensa transformação. Rio de Janeiro: Elsevier, 2011.

FERNANDES, Rosangela Ferreira Leal. Plano de carreira. Disponível em: <http:/ / www.unifil.br/portal/arquivos/publicacoes/paginas/2012/8/494_822_publipg. pdf>. Acesso em: 05 maio 2015.

GIL, Antônio Carlos. Como elaborar projetos de pesquisa. 5. ed. São Paulo: Atlas, 2010 . 
Didática no ensino superior. 1. ed. São Paulo: Atlas, 2012.

GRAMIGNA, Maria Rita. Modelo de competências e gestão dos talentos. São Paulo: Makron Books, 2002.

HUCZOK, Romeu; LEME, Rogério. Remuneração: cargos e salários ou competências? Rio de Janeiro: Qualitymark Editora, 2014.

LEME, Rogério. Aplicação prática de gestão de pessoas: mapeamento, treinamento, seleção avaliação e mensuração de resultados de treinamento. Rio de Janeiro: Qualitymark, 2005.

LOIOLA, R. Geração Y. Revista Galileu, São Paulo, n. 219, p. 50-53, out. 2009.

LOMBARDIA, P. G.; STEIN, G.; RAMÓN, J. Quem é a geração Y. Revista HSM Management, [S.l.], v. 70, 2008.

MALHOTRA, Naresc K.; MONTINGELLI JR., Nivaldo; FARIAS, Alfredo Alves de. Pesquisa de marketing: uma orientação aplicada. Porto Alegre: BookMan, 2012.

MALHOTRA, Naresh K. Pesquisa de marketing: uma orientação aplicada. 4. ed. Porto Alegre: Bookman, 2006.

MANACORDA, M. A. História da educação: da antiguidade aos nossos dias. Tradução de Gaetano Lo Monaco. 6. ed. São Paulo: Cortez, 1997.

MARQUEZE, Elaine Cristina; MORENO, Claudia Roberta de Castro. Satisfação no trabalho - uma breve revisão, 2005. Disponível em: <http:/ / www.scielo.br/pdf/ rbso/v30n112/07.pdf>. Acesso em: 04 out. 2015.

MARCONI, Marina de Andrade; LAKATOS, Eva Maria. Fundamentos de Metodologia Científica. 7. ed. São Paulo: Atlas, 2010.

MASCARENHAS, Cláudia Rafaela. O planejamento de carreiras sob a ótica dos estudantes de administração. 2008. Disponível em: <http:/ / www.administradores. com.br/_resources/files/_modules/academics/academics_3815_20110207223214ca3c. doc>. Acesso em: 02 mar. 2015.

MENDES, T. Geração Y: forjada pelas novas tecnologias. Revista Brasileira de Administração, São Paulo: CFA, n. 91, p. 52-54, nov./dez. 2012.

OLIVEIRA, Djalma de Pinho Rebouças de. Plano de carreira: foco no indivíduo: como elaborar e aplicar para ser um profissional de sucesso. 2. ed. São Paulo: Atlas, 2013.

OLIVEIRA, Sidnei. Geração Y: o nascimento de uma nova versão de líderes. São Paulo: Integrare Editora, 2010.

PONTES, Benedito Rodrigues. Administração de cargos e salários. 9. ed. São Paulo: LTr, 2002. 
RIBEIRO, Aicha et al. Plano de carreira: um estudo sobre as expectativas de crescimento profissional em duas empresas em Presidente Prudente, 2009. Disponível em: <http:/ / www.uniesp.edu.br/revista/revista7/pdf/20_plano_carreira.pdf $>$. Acesso em: 05 maio 2015.

ROBBINS, S. P. Comportamento organizacional. 9. ed. São Paulo: Prentice Hall, 2002.

ROESCH, Sylvia Maria Azevedo. Projetos de estágio e de pesquisa em administração: guia para estágios, trabalhos de conclusão, dissertações e estudos de caso. 3. ed. São Paulo: Atlas, 2013.

SANTOS, A. L. dos. A geração Y nas organizações complexas: um estudo exploratório sobre a gestão dos jovens nas empresas. Dissertação. (Programa de Pós-Graduação em Administração). Universidade de São Paulo. 2011. 154 f. São Paulo, 2011. Disponível em: <www.teses.usp.br/teses/disponiveis/12/12139/.../AndreLaizodosSantos.pdf >. Acesso em: 05 maio 2015.

SHIYASHIKI, Eduardo. A geração Z e o mercado de trabalho. 2009. Disponível em: $<$ wWw.administradores.com.br>. Acesso em: 05 maio 2015.

SOUZA, Sérgio Luiz Baena de. 2011. Fatores que influenciam os consumidores da Geração "Z" na compra de produtos eletrônicos. Dissertação (Mestrado em Administração). Universidade Potiguar, Natal. Disponível em: <https:/ / unp.br/ wp-content/uploads/2013/12/S\%C3\%A9rgio-Luiz-Baena-de-Souza-Fatores-QueInfluenciam-os-Consumidores-da-Gera $\% \mathrm{C} 3 \% \mathrm{~A} 7 \% \mathrm{C} 3 \% \mathrm{~A} 3 \mathrm{o}-\mathrm{Z}-\mathrm{Na}-\mathrm{Compra}$-deProdutos-Eletr\%C3\%B4nicos1.pdf>. Acesso em: 05 maio 2015.

TOZZI, Elisa. Como mudar de carreira aos 25, 35 e 45 anos. 154. ed. Revista Você S/A, São Paulo, 2011.

VANNUCHI, Camilo; DUARTE, Sara. Geração zapping. Revista ISTO É, São Paulo: Editora Três, n. 1659, jul. 2001.

VELOSO, Elza Fátima Rosa; DUTRA, Joel Souza; NAKATA, Lina Eiko. Percepção sobre carreiras inteligentes: diferenças entre as gerações $\mathrm{Y}, \mathrm{X}$ e baby boomers. 2008. XXXII Encontro da ANPAD. Disponível em: <http:/ / www.progep.org.br/ MelhoresEmpresas/InfoDocs/VELOSO\%20E_2008_Percep \%C3\%A7\%C3\%A3o\%20 sobre $\% 20$ carreiras $\% 20$ inteligentes_diferen $\%$ C3 $\%$ A7as $\% 20$ entre $\% 20$ as $\% 20$ gera $\%$ C3\%A7\%C3\%B5es $\% 20 Y, \% 20 X \% 20 \mathrm{e} \% 20$ baby $\% 20$ boomers.pdf $>$. Acesso em: 05 maio 2015.

WERTHER JR, William B.; DAVIS, Keith. Administração de pessoal e recursos humanos. Tradução de Auriphebo Berrance Simões. São Paulo: McGraw-Hill, 1983.

WOOD JUNIOR, T.; PICARELLI FILHO, V. Remuneração e carreira por habilidades e por competências: preparando a organização para a era das empresas de conhecimento intensivo. 3. ed. São Paulo: Atlas, 2004. 